\title{
Variability of antibiotic susceptibility and toxin production of Staphylococcus aureus strains isolated from skin, soft tissue, and bone related infections
}

\author{
Haziz Sina', Théodora A Ahoyo ${ }^{2}$, Wardi Moussaoui ${ }^{3}$, Daniel Keller ${ }^{3}$, Honoré S Bankolé ${ }^{4}$, Yves Barogui ${ }^{5}$, \\ Ymkje Stienstra ${ }^{6}$, Simeon $O$ Kotchoni $^{7}$, Gilles Prévost ${ }^{3}$ and Lamine Baba-Moussa ${ }^{{ }^{*}}$
}

\begin{abstract}
Background: Staphylococcus aureus is an opportunistic commensal bacterium that mostly colonizes the skin and soft tissues. The pathogenicity of $S$. aureus is due to both its ability to resist antibiotics, and the production of toxins. Here, we characterize a group of genes responsible for toxin production and antibiotic resistance of $S$. aureus strains isolated from skin, soft tissue, and bone related infections.

Results: A total of 136 S. aureus strains were collected from five different types of infection: furuncles, pyomyositis, abscesses, Buruli ulcers, and osteomyelitis, from hospital admissions and out-patients in Benin. All strains were resistant to benzyl penicillin, while $25 \%$ were resistant to methicillin, and all showed sensitivity to vancomycin. Panton-Valentine leukocidin (PVL) was the most commonly produced virulence factor (70\%), followed by staphylococcal enterotoxin B (44\%). Exfoliative toxin B was produced by $1.3 \%$ of the strains, and was only found in isolates from Buruli ulcers. The tsst-1, sec, and seh genes were rarely detected $(\leq 1 \%)$.

Conclusions: This study provides new insight into the prevalence of toxin and antibiotic resistance genes in S. aureus strains responsible for skin, soft tissue, and bone infections. Our results showed that PVL was strongly associated with pyomyositis and osteomyelitis, and that there is a high prevalence of PVL-MRSA skin infections in Benin.
\end{abstract}

Keywords: S. aureus, MRSA, PVL, Pyomyositis, Osteomyelitis, Skin infections, Benin, Africa

\section{Background}

Staphylococcus aureus is an opportunistic pathogen that mainly colonizes the nares and skin of up to $80 \%$ of the population [1]. S. aureus is a Gram-positive cocci that is frequently isolated in hospitals, and is responsible for diverse infections and toxicoses [2]. S. aureus is the most common cause of skin and soft-tissue infections (such as impetigo, furunculosis, and abscess), as well as systemic infections (such as pneumonia and endocarditis) [3]. The threat of $S$. aureus is not only due to its distribution

\footnotetext{
* Correspondence: laminesaid@yahoo.fr

'Laboratoire de Biologie et de Typage Moléculaire en Microbiologie; Faculté des Sciences et Techniques/Université d'Abomey-Calavi, Cotonou 05 BP 1604, BENIN

Full list of author information is available at the end of the article
}

and pathogenicity $[4,5]$, but also because of its ability to overcome antimicrobial agents [6-8].

Virulence factors produced by $S$. aureus render this organism highly pathogenic. The known virulence factors include exotoxins, such as exfoliative toxins (ETs), along with toxic shock syndrome toxin-1 (TSST-1), staphylococcal enterotoxins (SEs), leukocidins (Panton-Valentine leukocidin; PVL, LukE/D), and hemolysins $(\alpha, \beta, \gamma, \delta)$ [9]. Enterotoxins often cause food poisoning [10], while ETs (also called epidermolysins) act on the skin [11].

Among the leukocidins, PVL is an extracellular protein consisting of two subunits, $\mathrm{F}$ and $\mathrm{S}$, which act in concert and have leucocidal and dermonecrotic functions. The PVL toxin targets the outer membrane of polymorphonuclear cells, monocytes, and macrophages [12-15]. S. aureus 
strains that are positive for PVL are usually associated with skin and soft-tissue infections, and were first isolated in the 1960s [16-19]. PVL-positive strains are particularly associated with furuncles, accounting for $96 \%$ of cases [11,17,20], and approximately $90 \%$ of PVL-positive S. aureus strains were originally isolated from furuncles. PVL has also been associated with severe infections, including necrotizing pneumonia [19,21-24], osteomyelitis [25], and even cases of purpura fulminans [26]. PVL toxin was recently identified in Lemierre's syndrome [27], and in a case of Fournier's gangrene [28]. PVL has also been associated with community-acquired necrotizing and hemorrhagic pulmonary infections affecting previously healthy children and young adults [22,29].

Several antibiotics were routinely used in the treatment of $S$. aureus infections, contributing to the emergence of antibiotic-resistant strains. Widespread resistance severely complicates management of $S$. aureus infections. S. aureus strains that are resistant to methicillin (methicillin-resistant $S$. aureus, MRSA) are pervasive in the hospital environment, and have recently also caused a global epidemic of community-associated S. aureus (CA-MRSA) infections [30]. The changing trend of MRSA epidemiology, showed the use of PVL locus detection as a marker of CA-MRSA isolates, alongside with non multiresistant pattern and SCCmec type IV or V [31]. Vancomycin has been used successfully for over 50 years for the treatment of $S$. aureus infections, particularly those caused by MRSA strains [32]. However, vancomycin-resistant $S$. aureus (VRSA) and vancomycin-intermediate (VISA) strains have been reported, three decades after the introduction of vancomycin [33]. The presence of resistance genes may also affect toxin production.

The production of multiple virulence factors, as well as the presence of antibiotic resistance genes, makes $S$. aureus a highly pathogenic microorganism. The objective of this work was to study the susceptibility profile and toxin production of $S$. aureus strains isolated from various skin, soft tissue, and bone infections.

\section{Results}

\section{Prevalence of $S$. aureus strains according to the sample origin}

Using standard microbiological methods for identification of microorganisms; a total of 136 strains of S. aureus were collected during this study. The proportions of the strains varied depending on the five types of infection: furuncle, osteomyelitis, pyomyositis, abscess, and Buruli ulcer. Almost 37\% (50/136) of the collected strains originated from abscesses, followed by strains isolated from pyomyositis patients $(27 \%, 37 / 136)$, furuncles $(14 \%, 19 / 136)$, Buruli ulcers $(12 \%, 16 / 136)$, and osteomyelitis cases $(10 \%, 14 / 136)$.

\section{Susceptibility to antibiotics}

There was a wide range in the susceptibility of the isolates to the various antibiotics examined. All of the strains were resistant to benzyl penicillin, while other antibiotics (vancomycin, fusidic acid, fosfomycin, and linezolid) were active against some of the strains (Figure 1).

There was no significant difference in the antibiotic resistance of the strains based on their origin (Figure 2). $S$. aureus strains originating from pyomyositis (Figure 2a), furuncles (Figure 2b) and osteomyelitis cases (Figure 2c) were resistant to $4 / 17$ tested antibiotics (benzyl penicillin, rifampincin, tetracycline, and trimetroprim/sulfamethoxazol), while strains originating from abscesses and Buruli ulcer were strongly resistant to respectively $13 / 17$ and $7 /$ 17 of the tested antibiotics (Figure $2 \mathrm{~d}$, e). Of the 136 isolated S. aureus strains, 34 (25\%) were resistant to oxacillin (MRSA), while none of the strains showed resistance to vancomycin (VRSA). The oxacillin-resistant strains were all isolated from abscesses and Buruli ulcers.

Toxins production and/or presence of their encoding genes There was a significant difference in the production and/or the presence of genes encoding the 12 toxins ( $p$ $<0.0001)$. Thus, a significant number of strains $(70.0 \%)$ were capable of producing PVL, followed by the production of staphylococcal enterotoxin B (SEB) (44.3\%). None of the strains contained the genes responsible for exfoliative toxin B (ETB) or staphylococcal enterotoxin D (SED) production, while the ability to produce staphylococcal enterotoxins $\mathrm{C}$ and $\mathrm{E}$ (SEC, SEE), as well as the toxic shock syndrome toxin (TSST), was detected in

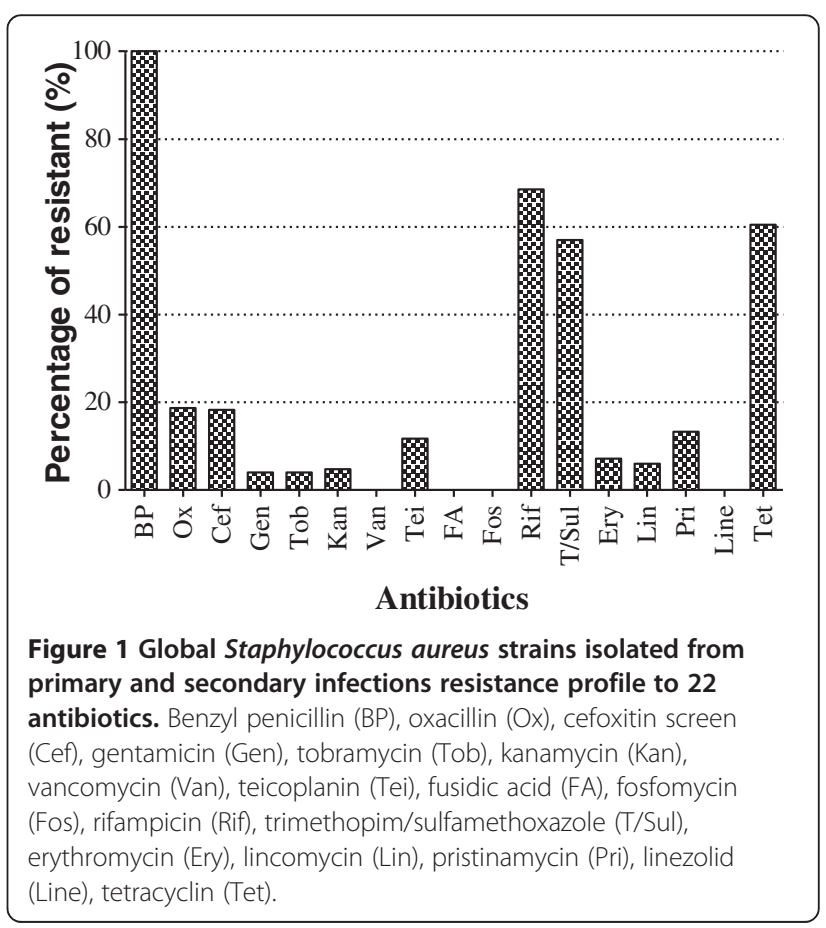




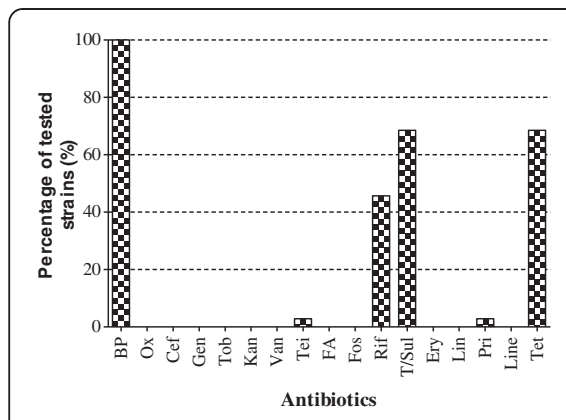

a. Pyomyositis

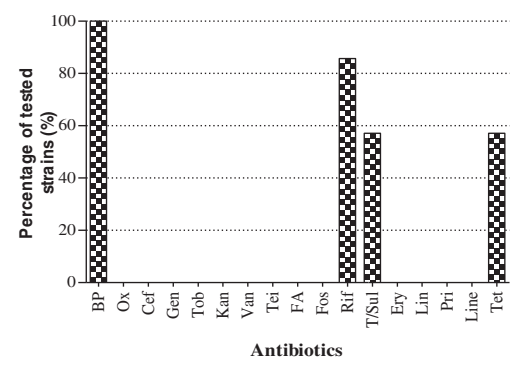

d. Osteomyelitis

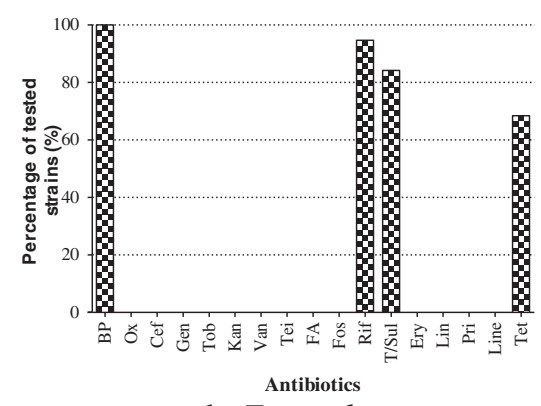

b. Furuncle



e. Buruli ulcer



c. Abscess

Figure 2 Staphylococcus aureus strains resistance profile to 22 antibiotics according to their origin. Benzyl penicillin (BP), Oxacillin (Ox), cefoxitin screen (Cef), gentamicin (Gen), tobramycin (Tob), kanamycin (Kan), vancomycin (Van), teicoplanin (Tei), fusidic acid (FA), fosfomycin (Fos), rifampicin (Rif), trimethopim/sulfamethoxazole (T/Sul), erythromycin (Ery), lincomycin (Lin), pristinamycin (Pri), linezolid (Line), tetracyclin (Tet).

$<1 \%$ of strains (Figure 3). The observed difference was related to the origin of the $S$. aureus strains. PVL was the most commonly produced toxin, regardless of the origin of the strains (Figure 4). PVL toxin was particularly prevalent in strains isolated from furuncles (89.5\%)

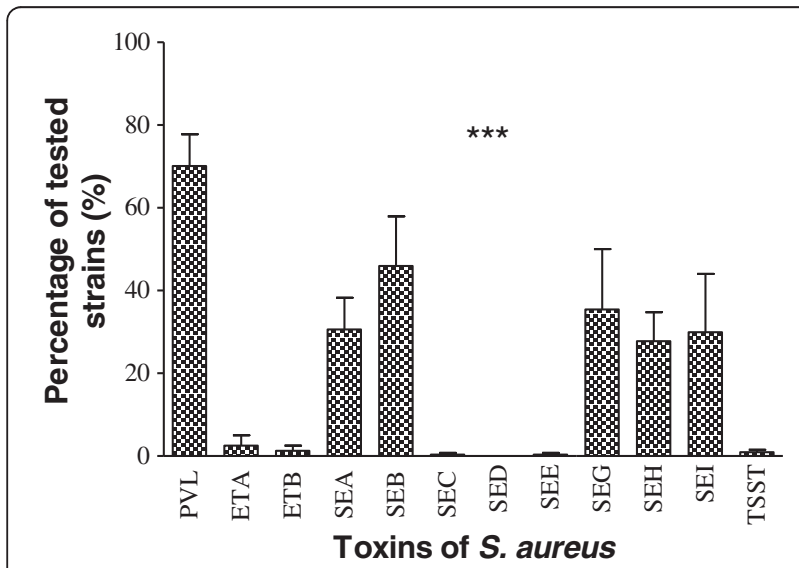

Figure 3 Toxins production by the Staphylococcus aureus strains isolated from primary and secondary infections. PVL: Panton-Valentine Leukocidin; ETA: Exfoliative Toxin A; ETB: Exfoliative Toxin B; SEA: staphylococcal enterotoxin A; SEB: staphylococcal enterotoxin B; SEC: staphylococcal enterotoxin C; SED: staphylococcal enterotoxin D; SEE: staphylococcal enterotoxin E; SEG: staphylococcal enterotoxin G; SEH: staphylococcal enterotoxin H; SEl: staphylococcal enterotoxin l; TSST: Toxic-shock syndrome Toxin. Means \pm standard deviations (SD) for three experiments are given. ***: $p^{<} 0.0001$. and pymyositis patients (89.2\%). Other toxins were produced in various proportions depending on the origin of the strain $(\mathrm{p}<0.0001)$. There was a significant difference in the detection of genes encoding toxins in MRSA strains (Figure 5).

\section{Discussion}

The $S$. aureus stains analyzed in this study displayed a wide range of sensitivity to the 17 tested antibiotics. Generally, benzyl penicillin was not efficient in controlling the strains (Figure 1). This is consistent with previous reports showing high rates of $S$. aureus resistance (>90\%) to benzyl penicillin $[34,35]$, suggesting that this antibiotic, one of the first to be introduced, is no longer effective against $S$. aureus [36]. A very high proportion of strains showed resistance to rifampicin (67\%), tetracycline (60\%), and trimetroprim/sulfamethoxazol (57\%). This finding is consistent with previous studies performed in Africa [37-40]. The high proportion of strains showing resistance to penicillin and three other antibiotics may be explained by the practice of patient self-medication in Benin, and by the availability and low price of the antibiotics. These antibiotics can be bought without prescription, especially in developing countries. In our in vitro study, 4/17 tested antibiotics (vancomycin, fusidic acid, fosfomycin, and linezolid) were effective against all the $S$. aureus strains.

The collection of strains isolated from abscesses was sensitive to only four of the 17 tested antibiotics. However, strains isolated from furuncles (Figure 2b) and 


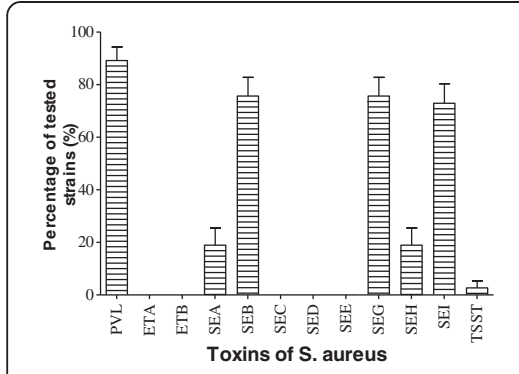

a. Pyomyositis

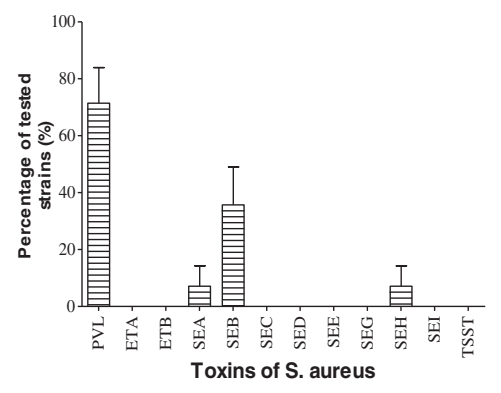

d. Osteomyelitis



b. Furuncle

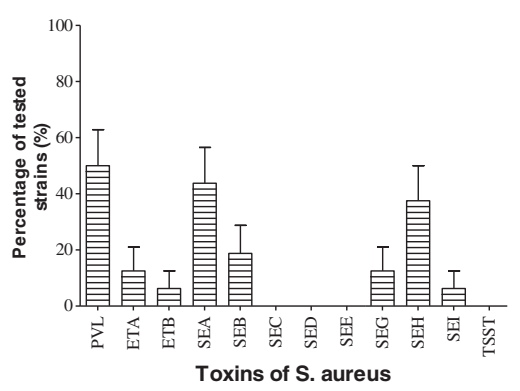

e. Buruli ulcer

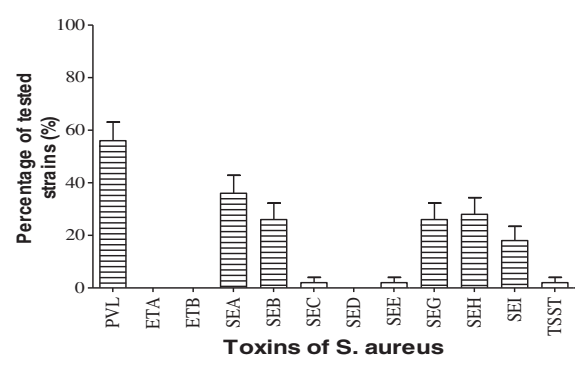

c. Abscess

Figure 4 Specificity of the toxins production by the $S$. aureus strains isolated from primary and secondary infections. PVL: PantonValentine Leukocidin; ETA: Exfoliative Toxin A; ETB: Exfoliative Toxin B; SEA: staphylococcal enterotoxin A; SEB: staphylococcal enterotoxin B; SEC: staphylococcal enterotoxin C; SED: staphylococcal enterotoxin D; SEE: staphylococcal enterotoxin E; SEG: staphylococcal enterotoxin G; SEH: staphylococcal enterotoxin H; SEI: staphylococcal enterotoxin I; TSST: Toxic-shock syndrome Toxin. Means \pm standard deviations (SD) for three experiments are given.

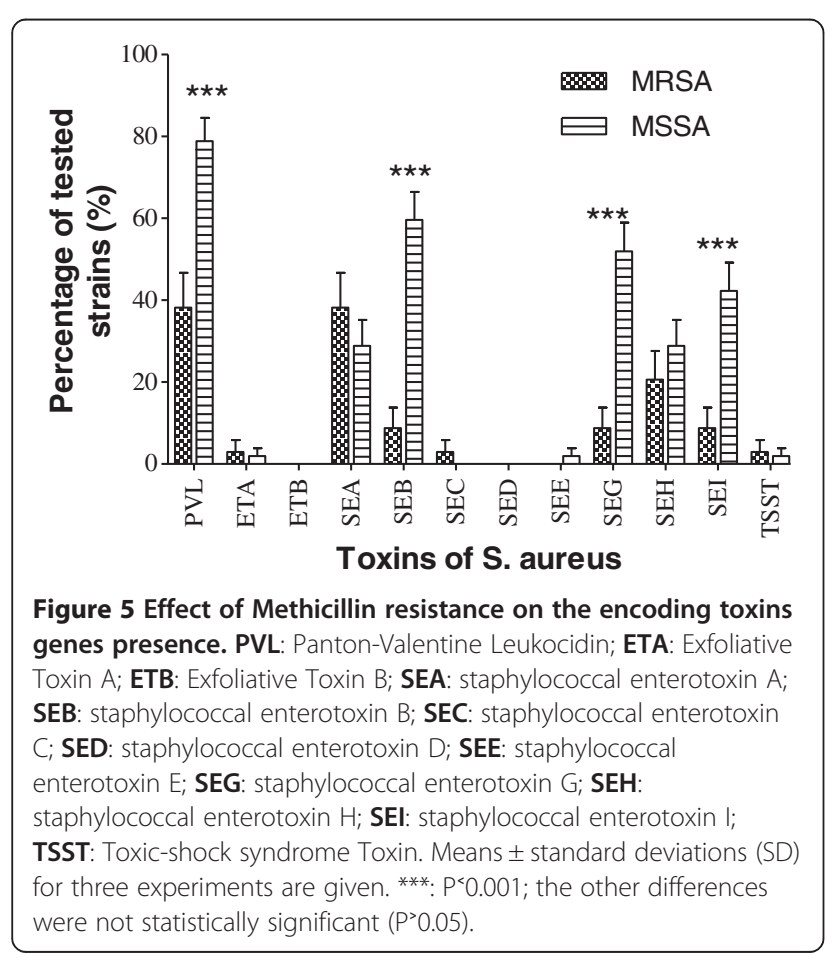

osteomyelitis patients (Figure 2d) were sensitive to 13 antibiotics (Figure 2). This result can likely be attributed to the origin of the strains. In our study, the samples collected from furuncles and osteomyelitis patients were from an extra-hospital community origin. Indeed, the selection pressure observed when using antibiotics in a hospital environment causes nosocomial strains to develop multi-resistance, in contrast to strains of community origin.

Of the 136 tested strains, 34 (25\%) were resistant to oxacillin. This proportion of resistant strains appears to have increased steadily in Benin, compared with the recorded resistance rate of $11.6 \%$ in 1999 [40]. However, the overall proportion of oxacillin-resistant strains in Benin is still low compared to surrounding countries [41], even though methicillin is the preferred antibiotic for treatment of staphylococcal infections [42]. To efficiently control MRSA, vancomycin is recommended [43], and in our study we observed no resistance to vancomycin. Fortunately, vancomycin remains active against methicillin resistant strains of $S$. aureus.

In the current study of $S$. aureus strains isolated from skin, soft tissue, and bone related infections, PVL was the most prevalent toxin in our collection $(70.0 \%$ of strains), followed by SEB (44.3\%), SEG (35.5\%), SEA (32.0\%), SEH (28.8\%), and SEI (28.9\%). The genes encoding ETB and SED were not detected in any of the 
strains, while the SEE $(0.8 \%)$, SEC $(0.6 \%)$, and TSST (1\%) genes were detected, but at a very low rate (Figure 3). This high detection frequency of the gene encoding PVL $(\mathrm{p}<0.0001)$ was observed throughout the analysis, regardless of the origin of the sample (Figure 4). PVL appears to be a primordial toxin of $S$. aureus strains associated with skin, soft tissue, and bone related infections. These results are lower than the $96 \%$ of PVLpositive production strains we observed among $S$. aureus isolated from furuncle [20]. But the prevalence of PVLpositive $S$. aureus obtained in our study is higher than the $52.1 \%$ observed in Nigeria [44] and in cape Verdes Island [45]. The observe differences observed can be explain by the fact that in our study, we use various kind of strains. However, our result is close to the $72 \%$ obtained in Algeria [46]. Then, comparing with the other studies, we can say that the prevalence level of PVL ocus varies with geographical location, and clinical specimen [47] In the clinical field, PVL-positive S. aureus strains are more pathogenic than PVL-negative strains [22]. This is explained by the fact that the lytic activity of PVL directly affects monocytes, macrophages, polynuclear neutrophils, and metamyelocytes, although erythrocytes are not lysed by PVL [48]. PVL toxin is known to have a cytolytic effect, and as such polynuclear neutrophils were identified as important indicators of staphylococcal virulence [16]. Moreover, the cytolytic activity of PVL is observed at high toxin concentrations, while apoptosis is observed at low concentrations [49].

Regarding the ETs, only the gene encoding epidermolysin A (ETA) was detected, and in all cases the $S$. aureus strains were isolated from Buruli ulcers (Figure 4e). Such specific production of ETA by Buruli ulcers may be explained by the fact that ETs are known to be serine active proteases, with their activity highly specialized for desmoglein-1, an important epidermal protein [50,51]. Therefore, the production of ETA by $S$. aureus strains from Buruli ulcers indicates a secondary role for $S$. aureus in the development of these ulcers, which are predominantly caused by Mycobacterium ulcerans.

Of the eight genes encoding enterotoxins, three (SEC, SED, and SEE) were not detected at all, while three others (SEA, SEB, and SEH) were detected at various proportions, regardless of the origin of the strains (Figure 4). Based on the homology of their sequences, the three detected enterotoxin genes belong to three different groups [52]. This explains the diversity of enterotoxins produced by $S$. aureus isolated from skin infections. Those toxins associated with food poisoning have antigenic and emetic activities [53-55]. The presence of enterotoxin genes in the strains isolated from skin, soft tissue, and bone related infections may be explained by human or environmental contamination, through the presence of open wounds. Similar observations are reported for TSST- 1 , which is the most prevalent toxin in cases of food poisoning [56].

Our study revealed that resistance to methicillin negatively correlates with toxin production (Figure 5). The difference in toxin production was extremely significant for PVL and some enterotoxins (B, G, and I) ( $<<0.0001)$, and we observed that MSSA strains produced twice as many toxins as MRSA strains. These results suggest that the isolated strains were in majority Hospital acquired methicillin resistance $S$. aureus (HA-MRSA) because the communityacquired methicillin resistance $S$. aureus (CA-MRSA). Indeed, these CA-MRSA have an SCCmec type IV cassette conferring resistance to methicillin [57], and 77\% of them harbor genes for Panton- Valentine leukocidin (PVL) $[58,59]$. In addition, the prevalence of the genes for some toxins is higher in CA-MRSA than in HA-MRSA, suggesting that strains circulating in the community are more toxinogenic than hospital-associated strains [60]. Focusing on the duality of the observed activity between the resistance to methicillin and detection of the PVL-encoding gene, we may deduce that the resistance gene has a repressive activity against PVL. This observation was also made by Baldwin and Lowe [61], and mostly relates to HAMRSA strains. In addition, we found that the presence of the methicillin resistance gene negatively impacts the expression of the gene encoding PVL. The emergence of MRSA in the hospital acquired strains may be viewed as disadvantageous in the selection of strains producing toxins, notably PVL. Indeed, mecA-encoded methicillin resistance involves $\beta$-lactamase production [62], which is not favorable for bacterial development [63]. Although community-acquired MRSA infections are increasingly frequent, the use of alternative antibiotics, such as vancomycin or ofloxacin/ciprofloxacin, is not appropriate because of the risk of the development of resistance to these antibiotics. Vancomycin is usually not available because of high costs and the necessity for assessing drug levels in the blood. Studies on the use of vancomycin for prophylaxis in medical centers with high rates of MRSA show that the use of this antibiotic is controversial in preventing some infections.

\section{Conclusions}

Our study showed that for S. aureus strains isolated from skin, soft tissue, and bone related infections, resistance to antibiotics depends on the origin of the strain. We attempted to perform a correlation analysis between toxin production, resistance to antibiotics, and the origin of samples. The $S$. aureus strains examined in this study produced a variety of toxins, with PVL, one of the most severe $S$. aureus toxins, being the most common amongst all of the strains. Overall, it is desirable to integrate to the current morphological and biochemical diagnostic analysis with virulence factor screening to 
accurately diagnose infectious disease mediated by $S$. aureus. This integrated diagnostic strategy will help to efficiently treat patients affected by pathogenic $S$. aureus strains. This study concerning skin, soft tissue, and bone related infections should be extended to include other types of infections in Benin.

\section{Methods}

\section{Ethics statement}

Ethical clearance was obtained from the Ministry of Public health of Benin Republic under protocol number: 2959/MSP/DC/SG/DRH/SPREA-05-2002. But it was important to notice that, the strains were de-identified and analyzed anonymously and the strains, not a human, were studied.

\section{Samples collection}

Clinical Staphylococcus aureus samples were collected from patients with skin, soft tissue at the National University Hospital of Cotonou (Benin) for various bacteriological screenings in routine, from November 2009 to March 2011. The incidence of secondary infections in Burili ulcer is unknown; antibiotics may be frequently prescribed for this indication. It is equally unknown which bacteria these antibiotics should target and what the sensitivity of these bacteria is. So the samples from Burili ulcer were screened for S. aureus. Theses samples were carried out during a prospective study made in a village of Lalo in Benin. Osteomyelitis and pyomyositis samples were collected during a prospective study made in a Hlagba Ouassa village in Benin. So these strains are considered as community strains and the others sample were isolated in hospital as stated previously.

\section{S. aureus' identification}

Standard microbiological methods for identification of microorganisms were applied. All swabs were inoculated onto mannitol salt agar, incubated at $37^{\circ} \mathrm{C}$ and inspected visually for three days. Any suspected colony was subcultured on tryptic soy agar (bioMérieux) and identified by subsequent Gram staining, catalase test and Slidex Staph Plus (bioMérieux) and the coagulase test with the rabbit plasma [64]. Bacterial identification was performed by colony isolation on sheep blood agar plates and the automated Vitek 2 system.

Table 1 Primers sequences used in this study for the detection of genes encoding toxins

\begin{tabular}{|c|c|c|c|c|}
\hline Primers & Sequences & Polarity & Expected fragment (base pair) & Accession $\mathrm{N}^{\circ}$ \\
\hline \multirow[t]{2}{*}{ eta } & 5'-GCAGGTGTTGATTTAGCATT-3' & Sens & 93 & A8658-043 \\
\hline & 5'-AGATGTCCCTATTITTGCTG-3' & Antisens & & A8658-044 \\
\hline \multirow[t]{2}{*}{ etb } & 5'-ACCCCTGTTCCCTTATCATC-3' & Sens & 226 & A8659-036 \\
\hline & 5'-GTTITGGCTGCTTCTCTTG-3' & Antisens & & A8659-037 \\
\hline \multirow[t]{2}{*}{ Ipv } & 5'-AAAATGCCACTGTTATCCAGAGGTA-3' & Sens & 433 & A8658-029 \\
\hline & 5'-TTTGCAGCGTTTTGTTTTCG-3' & Antisens & & A8658-030 \\
\hline \multirow[t]{2}{*}{ sea } & 5'-ATGGTTATCAATGTGCGGGTGIIIIICCAAACAAAAC-3' & Sens & 520 & A8658-031 \\
\hline & 5'-TGAATACTGTCCTTGAGCACCAIIIIITCGTAATTAAC-3' & Antisens & & A8658-032 \\
\hline \multirow[t]{2}{*}{ seb } & 5'-TGGTATGACATGATGCCTGCACIIIIGATAAATTTGAC-3' & Sens & 163 & A8658-033 \\
\hline & 5'-AGGTACTCTATAAGTGCCTGCCTIIIIIACTAACTCTT-3' & Antisens & & A8658-034 \\
\hline \multirow[t]{2}{*}{$\sec$} & 5'-GATGAAGTAGTTGATGTGTATGGATCIIIIACTATGTAAAC-3' & Sens & 283 & A8658-035 \\
\hline & 5'-AGATTGGTCAAACTTATCGCCTGGIIIIGGATCATATC-3' & Antisens & & A8658-036 \\
\hline \multirow[t]{2}{*}{ sed } & 5'-CTGAATTAAGTAGTACCGCGCTIIIIIATATGAAAC-3' & Sens & 384 & A8658-037 \\
\hline & 5'-TCCTIITGCAAATAGCGCCTTGIIIIIGCATCTAATTC-3' & Antisens & & A8658-038 \\
\hline \multirow[t]{2}{*}{ see } & 5'-CTTACCGCCAAAGCTGTCG-3' & Sens & 159 & A8658-039 \\
\hline & 5'-GTCCACTTGTAAATGGTAGCGAGAA-3' & Antisens & & A8658-040 \\
\hline \multirow[t]{2}{*}{ seg } & 5'-AATTATGTGAATGCTCAACCCGAT-3' & Sens & 408 & HA01804615 \\
\hline & 5'-CTITAGTGAGCCAGTGTCTTGCTTTG-3' & Antisens & & HA01804616 \\
\hline \multirow[t]{2}{*}{ seh } & 5'- CATCTACCCAAACATTAGCACC-3' & Sens & 222 & HA01804617 \\
\hline & 5'-AGAAATCAAGGTGATAGTGGCAA-3' & Antisens & & HA01804618 \\
\hline \multirow[t]{2}{*}{ sei } & 5'-AGGCGTCACAGATAAAAACCTACCIIIICAAATCAACTC-3' & Sens & 454 & HA01804619 \\
\hline & 5'-ACAAGGACCATTATAATCAATGCCIIIITATCCAGTTTC-3' & Antisens & & HA01804620 \\
\hline \multirow[t]{2}{*}{ tsst-1 } & 5'-ACCCCTGCCTITCCATCATC-3' & Sens & 209 & A8658-041 \\
\hline & 5'-TTाTCAGTATTTGTAACGCC-3' & Antisens & & A8658-042 \\
\hline
\end{tabular}




\section{Antibiotic susceptibility}

Antimicrobial susceptibility was determined by the disc diffusion method of Kirby-Bauer on agar Mueller-Hinton (bioMérieux, Marcy l'Etoile, France) as recommended by the Antibiogram Committee of the French Microbiology Society (CASFM) [65]. After $24 \mathrm{~h}$ at $37^{\circ} \mathrm{C}$, the zone of inhibition was measured. Susceptibility to vancomycin was confirmed by broth microdilution methodology as described by the Clinical and Laboratory Standards Institute (CLSI) [66]. For susceptibility to oxacillin, an inoculum of $10^{7} \mathrm{CFU} / \mathrm{ml}$ was prepared and the plate was incubated at $37^{\circ} \mathrm{C}$ for 24 hours on Mueller-Hinton agar $+2 \% \mathrm{NaCl}$. Antibiotic disks were obtained from Biorad, Marne la Coquette, France.

The 17 tested antibiotics were: benzyl penicillin (10 $\mathrm{UI})$, oxacillin $(5 \mu \mathrm{g})$, cefoxitin screen $(30 \mu \mathrm{g})$, gentamicin (10 UI), tobramycin $(10 \mu \mathrm{g})$, kanamycin $(30 \mu \mathrm{g})$, vancomycin $(30 \mu \mathrm{g})$, teicoplanin $(30 \mu \mathrm{g})$, fusidic acid $(10 \mu \mathrm{g})$, fosfomycin $(50 \mu \mathrm{g})$, rifampicin $(30 \mu \mathrm{g})$, trimethoprim/ sulfamethoxazole $(1.25 / 23.75 \mu \mathrm{g})$, erythromycin $(15 \mu \mathrm{g})$, lincomycin $(30 \mu \mathrm{g})$, pristinamycin $(15 \mu \mathrm{g})$, linezolid $(30$ $\mu \mathrm{g})$ and tetracyclin (30 UI).

\section{Toxin detection}

\section{Phenotypic detection of toxins}

For the phenotypic detection of toxins radial gel immunodiffusion was performed. The production of PantonValentine Leukocidin (PVL) and epidermolysins A (ETA) and B (ETB) were evidenced from culture supernatants after $18 \mathrm{~h}$ of growth in Yeast Casamino-acid Pyruvate (YCP) medium [67] by radial gel immunodiffusion in $0.6 \%(\mathrm{wt} / \mathrm{vol})$ agarose with component-specific rabbit polyclonal and affinity-purified antibodies $[68,69]$.

\section{Genotype detection of toxins}

Presence of genes encoding for the 12 toxins, for which we don't have antibody, was detected by Multiplex PCR using specific primers (Table 1) previously used for [70]. Then, the genes encoding for enterotoxins A (sea), B (seb), C (sec), D (sed), E (see), G (seg), H (seh), I (sei) and tsst were analyzed. Additionally, genes encoding PVL, ETA and ETB were also detected. Briefly, total DNA was purified using QIAamp DNA Mini Kit (Qiagen, GmbH, Germany) with a Gene Amp PCR System 9700 (PerkinElmer, Norwalk, USA) and amplified in a total volume of $50 \mu \mathrm{l}$ containing 25 pmoles of each primer, $50 \mathrm{ng}$ of total DNA, $1.5 \mathrm{mM} \mathrm{MgCl}_{2}, 200 \mu \mathrm{M}$ of dNTP mixture, $1 \times$ PCR reaction Buffer and 5 units of Taq ${ }^{\mathrm{Tm}}$ DNA polymerase (Invitogen $\left.{ }^{\mathrm{Tm}}\right)$. The thermal cycling conditions included an initial denaturation step $\left(2 \min\right.$ at $\left.92^{\circ} \mathrm{C}\right)$ followed by 35 cycles of amplification comprising three steps: 2 min denaturation for $92^{\circ} \mathrm{C}, 1 \mathrm{~min}$ annealing at $50^{\circ} \mathrm{C}, 2$ min extension at $72^{\circ} \mathrm{C}$. The reaction was terminated with 3 min extension at $72^{\circ} \mathrm{C}$. PCR products were analysed by electrophoresis through $1.4 \%$ (wt/vol) agarose gel (Euromedex, Mundolsheim, France).

\section{Staphylococcal enterotoxins production (SEA, SEB, SEC, SED, SEE, SEG, SEH, SEI) by Bio-Plex Assay (xMAP Multiplex assay)}

The centrifuged supernatant $(3 \mathrm{ml})$ of $S$. aureus grown on $\mathrm{BHI}$ at $37^{\circ} \mathrm{C}$ (night) was recovered and diluted $1 / 2$ in TBS-Tween20-IgG rabbit nonspecific at $100 \mu \mathrm{g} / \mathrm{mL}$, and incubated for $30 \mathrm{~min}$ at room temperature. The Bio-Plex assays consisted of three incubation steps that were performed into flat-bottom Multiscreen microplates (pores diameter $=1.2 \mu \mathrm{m}$, Millipore) according to the previous describe method [71]. Any steps were separated by three washes into TBS-Tween 20.

\section{Statistical analysis}

Microsoft Excel Spreadsheet has been used for data processing. For comparison tests of positive isolates of each patient group, we used the Student $\mathrm{T}$ test, and the Fischer's test for lower number series (GraphPad Prism 5). $\mathrm{P}<0.05$ was considered statistically significant.

\section{Competing interests}

Authors declare no conflict of interest.

\section{Authors' contributions}

Conception and design of the study: LB-M and GP. Acquisition of data: HS, AT-A, WM, YB, HB. Analysis and interpretation of data: LB, GP, YS. Drafting the article: LB-M, SOK, and HS. Revising it critically for important intellectual content: LB-M, GP, SOK, YS. Final approval of the version to be submitted: All the co-authors. All authors read and approved the final manuscript.

\section{Acknowledgements}

This work was supported by Benin Government which granted Haziz Sina and by grant EA-4438 from "Direction de la Recherche et des Etudes Doctorales" of Unversity of Strasbourg in France.

\section{Author details}

${ }^{1}$ Laboratoire de Biologie et de Typage Moléculaire en Microbiologie; Faculté des Sciences et Techniques/Université d'Abomey-Calavi, Cotonou 05 BP 1604, BENIN. 'EPAC/ Université d'Abomey-Calavi, Cotonou 01 BP 526, BENIN 3Unité: EA-4438 Physiopathologie et Médecine, Institut de Bactériologie, 3 rue Koeberlé, Strasbourg F-67000, France. ${ }^{4}$ Laboratoire National de Santé Publique, Cotonou, Bénin. ${ }^{5}$ Programme National de Lutte contre I'Ulcère de Buruli, Cotonou, Benin. 'Department of Internal Medicine/Infectious Diseases, University of Groningen, University Medical Center Groningen, P.O. Box 30.001, Groningen 9700 RB, The Netherlands. ${ }^{7}$ Department of Biology and Center for Computational and Integrative Biology, Rutgers University, Camden NJ 08102, USA.

Received: 20 March 2013 Accepted: 7 August 2013 Published: 8 August 2013

\section{References}

1. Kluytmans A, van Belkum A, Verbrugh $\mathrm{H}$ : Nasal carriage of Staphylococcus aureus: epidemiology, underlying mechanisms, and associated risks. Clin Microbial Rev 1997, 10(3):505-520.

2. Nubel U, Roumagnac P, Feldkamp M, Song JH, Ko KS, Huang YC, Coombs G, Ip M, Westh H, Skov R, Struelens MJ, Goering RV, Strommenger B, Weller A, Witte W, Achtman M: Frequent emergence and limited geographic dispersal of methicillin-resistant Staphylococcus aureus. Proc Natl Acad Sci U S A 2008, 105:14130-14135. 
3. Holmes A, Ganner M, McGuane S, Pitt TL, Cookson BD, Kearns AM: Staphylococcus aureus Isolates Carrying Panton-Valentine Genes in England and Wales: Frequency, Characterization, and Association with Clinical Desease. J Clin Microbiol 2005, 43(5):2384-2390.

4. Baba-Moussa L, Anani L, Scheftel JM, Couturier M, Riegel P, Haikou N, Hounsou F, Monteil H, Sanni A, Prevost G: Virulence factors produced by strains of Staphylococcus aureus isolated from urinary tract infections. J Hosp Infect 2008, 68:32-38.

5. Baba-Moussa L, Ahissou H, Azokpota P, Assogba B, Atindéhou M, Anagonou S, Keller D, Sanni A, Prévost G: Toxins and adhesion factors associated with Staphylococcus aureus strains isolated from diarrheal patients in Benin. Afr J Biotechnol 2010, 9:604-611.

6. Bohach GA, Fast DJ, Nelson RD, Schlievert PM: Staphylococcal and streptococcal pyrogenic toxins involved in toxic shock syndrome and related illnesses. Crit Rev Microbiol 1990, 17:251-272.

7. Breneman DL: Bacterial infection of the skin and soft tissues and their treatment. Curr Opin Infect Dis 1993, 6:678-682.

8. Murray DL, Ohlendorf DH, Schlievert PM: Staphylococcal and streptococcal superantigens: their role in human diseases. ASM News 1995, 61:229-235.

9. Dinges MM, Orwin PM, Schlievert PM: Exotoxins of Staphylococcus aureus. Clin Microbiol Rev 2000, 13:16-34.

10. Barg NL, Harris T: Toxin-mediated syndromes. In The staphylococci in human disease. Edited by Crossley KB, Archer GL. New York: Churchill Livingstone; 1997:527-544.

11. Durupt F, Mayor L, Bes M, Reverdy ME, Vandenesch F, Thomas L, Etienne J: Prevalence of Staphylococcus aureus toxins and nasal carriage in furuncles and impetigo. Br J Dermatol 2007, 157:1161-1167.

12. Gladstone GP, Van Heyningen WE: Staphylococcal leucocidins. Br J Exp Pathol 1957, 38:123-137.

13. Woodin AM: Fractionation of a leucocidin from Staphylococcus aureus. Bioch J 1959, 73:225-237.

14. Szmigielski S, Sobiczewska E, Prévost G, Monteil H, Colin DA, Jeljaszewicz J: Effect of purified staphylococcal leukocidal toxins on isolated blood polymorphonuclear leukocytes and peritoneal macrophages in vitro. Zentralbl Bakteriol 1998, 288:383-394.

15. Hongo I, Baba T, Oishi K, Morimoto Y, Ito T, Hiramatsu K: Phenol-soluble modulin alpha 3 enhances the human neutrophil lysis mediated by Panton- Valentine leukocidin. J Infec Dis 2009, 200:715-723.

16. Cribier B, Prevost G, Couppie P, Finck-Barbancon V, Grosshans E, Piemont $Y$ : Staphylococcus aureus leukocidin: a new virulence factor in cutaneous infections? An epidemiological and experimental study. Dermatology 1992, 185:175-180.

17. Couppié $P$, Cribier B, Prévost G, Grosshans E, Piémont Y: Leucocidin from Staphylococcus aureus and cutaneous infections: an epidemiological study. Arch Dermatol 1994, 130:1208-1209.

18. Prevost G, Cribier B, Couppie P, Petiau P, Supersac G, Finck-Barbancon V, Monteil $\mathrm{H}$, Piemont $\mathrm{Y}$ : Panton-Valentine leucocidin and gammahemolysin from Staphylococcus aureus ATCC 49775 are encoded by distinct genetic loci and have different biological activities. Infect Immun 1995, 63:4121-4129.

19. Lina G, Piémont Y, Godail-Gamot F, Bès M, Peter MO, Gauduchon V Vandenesh F, Etienne J: Involvement of Panton Valentine leukocidineproducing Staphylococcus aureus in primary skin infections and pneumonia. Clin Infect Dis 1999, 29:1128-1132.

20. Baba-Moussa L, Sina H, Scheftel JM, Moreau B, Sainte-Marie D, Kotchoni SO, Prevost G, Couppie P: Staphylococcal Panton-Valentine leucocidin as a major virulence factor associated to furuncles. PLoS One 2011, 6:e25716.

21. Couppié P, Hommel D, Prévost G, Godart MC, Moreau B, Sainte- Marie D, Peneau C, Hulin A, Monteil H, Pradinaud R: Septicémie à Staphylococcus aureus, furoncle et leucocidine de Panton et Valentine: 3 observations. Ann Dermatol Venereol 1997, 124:684-686.

22. Gillet $Y$, Issartel B, Vanhems P, Fournet JC, Lina G, Bes M, Vandenesch F, Piémont $Y$, Brousse N, Floret D, Etienne J: Association between Staphylococcus aureus strains carrying gene for Panton Valentin leukocidin and highly lethal necrotising pneumonia in young immunocompetent patients. Lancet 2002, 359:753-759.

23. Labandeira-Rey M, Couzon F, Boisset S, Brown EL, Bes M, Benito Y, Barbu EM, Vazquez V, Höök M, Etienne J, Vandenesch F, Bowden MG: Staphylococcus aureus Panton Valentine leukocidin causes necrotizing pneumonia. science 2007, 315(5815):1130-1133.
24. Diep BA, Palazzolo-Ballance AM, Tattevin P, Basuino L, Braughton KR, Whitney AR, Chen L, Kreiswirth BN, Otto M, DeLeo FR, Chambers HF: Contribution of Panton Valentine leukocidin in community-associated methicillin-resistant Staphylococcus aureus pathogenesis. PLos One 2008, 3:e3198.

25. Gillet $Y$, Dohin B, Dumitrescu O, Lina G, Vandenesch F, Etienne J, Floret D: Osteoarticular infections with Staphylococcus aureus secreting Panton Valentine leucocidin. Arch Pediatr 2007, 14(Suppl 2):102-107.

26. Hussain A, Robinson GO, Malkin J, Duthie M, Kearns A, Perera N: Purpura fulminans in a child secondary to Panton Valentine leukocidinproducing Staphylococcus aureus. J Med Microbiol 2007, 56:1407-1409.

27. Shivashankar GH, Murukesh N, Varma MP, Sharif IM, Glynn G: Infection by Panton Valentine leukocidin-producing Staphylococcus aureus clinically mimicking Lemierre's syndrome. J Med Microbiol 2008, 57:118-120

28. Burton MJ, Shah P, Swiatlo E: Community-acquired methicillin resistant Staphylococcus aureus as a cause of Fournier's gangrene. J Med Sci 2008 335:327-328.

29. Dumitrescu O, Boisset S, Badiou C, Bes M, Benito Y, Reverdy ME, Vandenesch F, Etienne J, Lina G: Effect of antibiotics on Staphylococcus aureus producing Panton-Valentine leukocidin. Antimicrob Agents Chemother 2007, 51:1515-1519.

30. Deleo FR, Otto M, Kreiswirth BN, Chambers HF: Community-associated meticillin-resistant Staphylococcus aureus. Lancet 2010, 375:1557-1568.

31. Deurenberg RH, Stobberingh EE: The evolution of Staphylococcus aureus. Inf Genet Evol 2008, 8:747-763.

32. Holmes NE, Johnson PD, Howden BP: Relationship between VancomycinResistant Staphylococcus aureus, Vancomycin-Intermediate S. aureus, High Vancomycin MIC, and Outcome in Serious S. aureus Infections. J Clin Microbiol 2012, 50:2548-2552.

33. Hiramatsu K, Aritaka N, Hanaki H, Kawasaki S, Hosoda Y, Kobayashi I: Dissemination in Japanese hospitals of strains of $\mathrm{S}$. aureus heterogeneously resistant to vancomycin. Lancet 1997, 350:1670-1673.

34. Denton M, O'Connell B, Bernard P, Jarlier V, Wiliams Z, Santerre Henriksen A: The EPISA Study: antimicrobial susceptibility of Staphylococcus aureus causing primary or secondary skin and soft tissue infections in the community in France, the UK and Ireland. J Antimicrobial Chemother 2008, 61(3):586-588.

35. Elazhari M, Saile R, Dersi N, Timinouni M, Elmalki A, Zriouil SB, Hassar M, Zerouali K: Activité de 16 Antibiotiques vis-à-vis des Staphylococcus aureus communautaires à Casablanca (Maroc) et Prévalence des Souches Résistantes à la Méthicilline. Eur J Sci Res 2009, 30:128-137.

36. Cohen ML: Epidemiology of drug resistance: implications for a postantimicrobial era. Science 1992, 257:1050-1055.

37. Sina H, Baba-Moussa F, Ahoyo TA, Mousse W, Anagonou S, Gbenou JD, Prévost G, Kotchoni SO, Baba-Moussa L: Antibiotic susceptibility and Toxins production of Staphylococcus aureus isolated from clinical samples from Benin. Afr J Microbiol Res 2011, 5:2797-2808.

38. Randrianirina F, Soares JL, Ratsima E, Carod JF, Combe P, Grosjean P, Richard V, Talarmin A: In vitro activities of 18 antimicrobial agents against Staphylococcus aureus isolates from the Institut Pasteur of Madagascar. Ann Clin Microbiol Antimicrob 2007, 6:5.

39. Kesah C, Ben Redjeb S, Odugbemi TO, Boye CS, Dosso M, Ndinya Achola JO, Koulla-Shiro S, Benbachir M, Rahal K, Borg M: Prevalence of methicillinresistant Staphylococcus aureus in eight African hospitals and Malta. Clin Microbiol Infect 2003, 9:153-156.

40. Baba-Moussa L, Sanni A, Dagnra AY, Anagonou S, Prince-David M, Edoh V, Befort JJ, Prévost G, Monteil H: Approche épidémiologique de l'antibiorésistance et de la production de leucotoxines par les souches de Staphylococcus aureus isolées en Afrique de l'Ouest. Med Mal Infect 1999, 29(11):689-696.

41. Diekema DJ, Pfaller MA, Schmitz FJ, Smayevsky J, Bell J, Jones RN, Beach M: Survey of infections due to Staphylococcus species: frequency of occurrence and antimicrobial susceptibility of isolates collected in the United States, Canada, Latin America, Europe, and the Western Pacific region for the SENTRY Antimicrobial Surveillance Program, 1997-1999. Clin Infect Dis 2001, 32(suppl 2):114-132.

42. Belabbès H, Elmdaghri N, Hachimi K, Marih L, Zerouali K, Benbachir M: Résistance de Staphylococcus aureus isolé des infections communautaires et hospitalieres à Casablanca. Communication brève. Med Mal Infect 2001, 31:25-28. 
43. Maor Y, Hagin M, Belausov N, Keller N, Ben-David D, Rahav G: Clinical features of heteroresistant vancomycin-intermediate Staphylococcus aureus bacteremia versus those of methicillin-resistant S. aureus bacteremia. J Infect Dis 2009, 199:619-624.

44. Okon KO, Uba A, Oyawoye OM, Yusuf IZ, Adesina OO: Prevalence and Antibiotic susceptibility pattern of Panton-Valentine Leucocidin (PVL) positive Staphylococcus aureus Strains from clinical specimens in Northeastern Nigeria. Sierra Leone J Biomed Res 2012, 4(1):43-52.

45. Aires de Sousa M, Conceicao T, de Lancastre H: Unusually high prevalence of nosocomial Panton-Valentine leukocidin -positive Staphylococcus aureus isolates in Cape Verdes Island. J Clin Microbiol 2006, 44:37-3793.

46. Campbell SJ, Deshmukl HS, Nelson CL, Bae I: Genotypic characterization of Staphylococcus aureus isolates from a multinational trial of topical drugs for skin and skin stricture infections. J Clin Microbiol 2008, 46:678-684.

47. Goering RV, Shawar RM, Scangarella NE, OHara FP, Amrine-Madsen H, West JM, Dalessandro M, Becker JA, Walsh SL, Miller LA, van Horn SF, Thomas ES, Twynholm T: Molecular epidemiology of methicillin-resistant and methicillinsusceptible Staphylococcus aureus isolates from global clinical trial. J Clin Microbiol 2008, 9:2842-2847.

48. Prévost G, Mourey L, Colin DA, Menestrina G: Staphylococcal pore-forming toxins. Curr Top Microbiol Immunol 2001, 257:53-83.

49. Genestier AL, Michallet MC, Prevost G, Bellot G, Chalabreysse L, Peyrol S, Thivolet F, Etienne J, Lina G, Vallette FM, Vandenesch F, Genestier L: Staphylococcus aureus Panton-Valentine leukocidin directly targets mitochondria and induces Bax-independent apoptosis of human neutrophils. J Clin Invest 2005, 115:3117-3127.

50. Ladhani S: Understanding the mechanism of action of the exfoliative toxins of Staphylococcus aureus. FEMS Immunol Med Microbiol 2003, 39:181-189.

51. Prevost G, Couppie P, Monteil H: Staphylococcal epidermolysins. Curr Opin Infect Dis 2003, 16:71-76

52. Vandenesch F, Naimi T, Enright MC, Lina G, Nimmo GR, Heffernan H, Liassine N, Bes M, Greenland T, Reverdy ME, Etienne J: Community acquired methicillinresistant Staphylococcus aureus carrying Panton-Valentine leukocidin genes: worldwide emergence. Emerg Infect Dis 2003, 9:978-984.

53. Morris CA, Conway HD, Everall PH: Food-poisoning due to staphylococcal enterotoxin E. Lancet 1972, 2:1375-1376.

54. Chen TR, Chiou CS, Tsen HY: Use of Novel PCR Primers Specific to the Genes of Staphylococcal Enterotoxin G, H, I for the Survey of Staphylococcus aureus Strains Isolated From Food-Poisoning Cases and Food Samples in Taiwan. Int J Food Microbiol 2004, 92:189-197.

55. Ikeda T, Tamate N, Yamaguchi K, Makino S: Mass Outbreak of Food Poisoning Disease Caused by Small Amounts of Staphylococcal Enterotoxins A and H. Appl Environ Microbiol 2005, 71:2793-2795.

56. Daum RS, Ito T, Hiramatsu K, Hussain F, Mongkolrattanothai K, Jamklang M, Boyle-Vavra S: A novel methicillin-resistance cassette in communityacquired methicillin-resistant Staphylococcus aureus isolates of diverse genetic backgrounds. J Infect Dis 2002, 186:1344-1347.

57. Naimi TS, LeDell KH, Como-Sabetti K, et al: Comparison of com-munityand health care-associated methicillin-resistant Staphylococcus aureus infection. JAMA 2003, 290:2976-2984.

58. Buckingham SC, McDougal LK, Cathey LD, et al: Emergence of com-munity -associated methicillin-resistant Staphylococcus aureus at a Memphis, Tennessee Children's Hospital. Pediatr Infect Dis J 2004, 23:619-624.

59. Cosgrove SE, Sakoulas G, Perencevich EN, Schwaber MJ, Karchmer AW, Carmeli Y: Comparison of mortality associated with methicillin-resistant and methicillin-susceptible Staphylococcus aureus bacteremia: a metaanalysis. Clin Infect Dis 2003, 36:53-59.

60. Bergdoll MS, Crass BA, Reiser RF, Robbins RN, Davis JP: A New Staphylococcal Enterotoxin, Enterotoxin F, Associated with Toxic-Shock -Syndrome Staphylococcus aureus Isolates. Lancet 1981, 1:1017-1021.

61. Baldwin LN, Lowe AD: Panton-Valentine Leukocidin associated with community acquired methicillin resistant Staphylococcus aureus: a case report and review of interim guidelines. Anaesthesia 2008, 63:764-766.

62. Chambers HF: Methicillin resistance in staphylococci: molecular and biochemical basis and clinical implications. Clin Microbiol Rev 1997 10:781-791

63. Labischinski $\mathrm{H}$ : Consequences of the interaction of beta-lactam antibiotics with penicillin binding proteins from sensitive and resistant Staphylococcus aureus strains. Med Microbiol Immunol 1992, 181:241-265.
64. Cheesbrough M: District Laboratory Practice in Tropical Countries: Part 2. Cambridge, UK: Cambridge University Press; 2004:299-329.

65. Société Française de Microbiologie: Recommandations du Comité de l'Antibiogramme de la Société Française de Microbiologie.; 2012. http://www. sfm-microbiologie.org/UserFiles/file/CASFM/CASFM_2012.pdf.

66. Clinical and Laboratory Standards Institute: Methods for dilution antimicrobial susceptibility tests for bacteria that grow aerobically, Approved standard. 8th edition. Document M7-A8. Clinical and Laboratory Standards Institute Wayne: PA; 2009. ISBN ISBN 1-56238-689-1.

67. Gauduchon V, Werner S, Prévost G, Monteil H, Colin DA: Flow cytometric determination of Panton-Valentine leucocidin S component binding. Infect Immun 2001, 69:2390-2395.

68. Prévost $G$, Couppie $P$, Prévost $P$, Gayet $S$, Petiau P, Cribier B, Monteil H, Piemont Y: Epidemiological data on Staphylococcus aureus strains producing synergohymenotropic toxins. J Med Microbiol 1995, 42:237-245.

69. Gravet A, Colin DA, Keller D, Girardot R, Monteil H, Prevost G: Characterization of a novel structural member, LukE-LukD, of the bi-component staphylococcal leucotoxins family. FEBS Lett 1998, 436:202-208.

70. Jarraud S, Mougel C, Thioulouse J, Lina G, Meugnier H, Forey F, Nesme X, Etienne J, Vandenesch F: Relationships between Staphylococcus aureus genetic background, virulence factors, agr groups (alleles), and human disease. Infect Immun 2002, 70:631-641.

71. Joubert O, Keller D, Pinck A, Monteil H, Prevost G: Sensitive and specific detection of staphylococcal epidermolysins $A$ and $B$ in broth cultures by flow cytometry-assisted multiplex immunoassay. J Clin Microbiol 2005, 43:1076-1080.

\section{doi:10.1186/1471-2180-13-188}

Cite this article as: Sina et al:: Variability of antibiotic susceptibility and toxin production of Staphylococcus aureus strains isolated from skin, soft tissue, and bone related infections. BMC Microbiology 2013 13:188.

\section{Submit your next manuscript to BioMed Central and take full advantage of:}

- Convenient online submission

- Thorough peer review

- No space constraints or color figure charges

- Immediate publication on acceptance

- Inclusion in PubMed, CAS, Scopus and Google Scholar

- Research which is freely available for redistribution 